\title{
Online Convergence Behavior, Social Media Communications and Crisis Response: An Empirical Study of the 2015 Nepal Earthquake Police Twitter Project
}

\author{
Rajib Subba \\ Pacific Research Institute for \\ Information Systems and Management \\ rajib@hawaii.edu
}

\author{
Tung Bui \\ University of Hawai'i at Manoa \\ tungb@hawaii.edu
}

\begin{abstract}
Emergency response organizations such as the police are using social media as an additional channel to communicate with the general public in times of crisis. However, the utilization of social media with a free-style communication protocol by emergency response authorities for crisis response is still insufficiently understood. Who are the people they communicate with? What types of crisis-related information are shared with them? How do people react to these messages? How does the general public react to a social media run by a police organization? This paper uses the typology of convergence behaviors in emergency response as an attempt to categorize the public interaction with social media platforms. Furthermore, it uses the Situation Crisis Communication theory (SCCT) to analyze the crisis communication practices by a law enforcement agency. A content analysis of Nepal Police Tweets from the aftermath of the 2015 Nepal earthquake was conducted. It sought to understand (i) whether people who Tweet exhibit the same convergence behaviors as reported in the literature, (ii) how online participants communicate among and between the different crisis convergence behaviors, and (iii) what would be the best communication practices to assist crisis response efforts. Data show that convergence behaviors differed from intensity of appearances and communications and Tweets helped reconcile the differences in perceived emergency response needs between netizens and the authorities.
\end{abstract}

Keywords: Crisis response, communications in crisis management, convergence behaviors, and social media.

\section{Introduction}

This paper reports the findings of an empirical study of various types of social media communications between "authorities in charge of emergency responses" and the "netizens," in the aftermath of a major earthquake. Recent related research has used slightly different names for "authorities in charge of emergency responses": emergency responder [19]; emergency service agency [26]; public safety organization [29]; emergency management agency [28]; and first responder [54]. For the purpose of this study, we selected "authorities" because the first emergency responder in charge of using a social media was a police organization, which is widely recognized as a public authority. Also, in our research, we view netizens as online users who appreciate the value of pubic communications in supporting collaborative work [1]. By their very nature, these netizens are geographically dispersed, tend to surface online randomly, may or may not know each other, and may have real profiles or could be anonymous. Using a real-life situation, in which social media-Twitterwas used by a public authority, this study seeks to analyze the nature of communication using the typology of communications in the context of convergence behaviors initiated by [2]'s seminal work and additional work by [3] and subsequent studies that focus on online behaviors (e.g., $[4,5,6])$. In particular, this study investigated the interactions between the convergence behaviors of netizens and communication practices of an emergency response organization. Moreover this study explores how social media can be set up and used in crisis response by an emergency response organization.

\section{Social Media Communications and Crisis Response: Authorities vs. General Public}

As envisioned by [8] more than four decades ago, computer-supported communications including social media platforms have drastically changed the 
way people in society interact. Over $75 \%$ of Internet users use social media with 65 percent of Americans adults use social networking sites several times per day ${ }^{1}$.

In times of crises-whether natural or manmade-social media sites are "digital habitats" [7] where users converge to gather information and resources. As examples, netizens used the microblogging site Twitter for situation updates during the 2007 California wild fires [9, 10], the 2009 Red River floods, the 2009 Oklahoma Grassfires [11], the 2010-2011 Australian floods [12], the 2011 Japan tsunami [13], the 2014 Chile earthquake, [14] and the 2015 Nepal earthquake [15].

Ehnis and Bunker [16] have noticed that social media has become in recent times an important tool for emergency response organizations [17, 18, 19]. Even police organizations, which are considered as monocentric organizations [20], and have a unified command structure or single center of authority [21]; hierarchical structure [22, 23, 24]; and rank and file structure [25], are using social media as an additional channel for communication with the public $[16,19$, $26,27,28]$. They use social media to gather, share, and broadcast information during their policing work including crime investigations [27, 28, 29].

A conventional wisdom among authorities in charge of crisis situations is that lack of coordination and cooperation may hinder crisis management when many stakeholders including the general public are engaged in emergent crisis situations. They argue that without proper training and adequate resources, the authorized crisis responders and emergent volunteers, even with good intentions, would likely cause more complications than provide effective assistance. While this view seems reasonable in a small-scale situation, a disaster of sizable proportion-such as a major earthquake or tsunami-would be so overwhelming when it becomes inevitable that the general public get involved spontaneously. Events such as hurricane Katrina in the U.S., the recent tsunami in Japan, and the earthquakes in Haiti and Nepal are just a few examples that - like it or not, planned or unplanned authorities worked together with the general public, who converged spontaneously to disaster sites, to quickly deal with rescue and relief operations.

Fritz and Mathewson [2] presented five types of personal convergers: the returnees, the anxious, the helpers, the curious, and the exploiters,

\footnotetext{
${ }^{1}$ www.pewinternet.org
}

and [3] identified two additional types of convergers: the fans or supporters and the mourners and memorializers. Subba and Bui [6] suggested an additional convergence behavior, which they call the detectives. People show up for a number of reasons: enquiring about their properties they left behind; looking for their loved ones; offering physical help and mental support; curiously observing how the situation unfolds; possibly duping people with scams; cheering up the crisis responders; expressing sympathy to the victims; or informing authorities about exploiters. Authorized crisis responders generally see these spontaneous convergence behaviors during natural disasters as a source of problems because regulating spontaneous convergence behaviors can be a daunting task for them when trained manpower or monitoring mechanisms are in short supply [2, 3]. With the advent of information and communication technologies including social media, such situations get amplified as convergence behaviors parallel in cyberspace as well [4, 5, 6]. However, studies on social media engagement by police organizations with the netizens during and after crisis situations are limited $[16,26,30]$ despite a growing interest and the lack of knowledge and expertise on how to leverage the social media for crisis response effectively [19].

\section{Theoretical and Analytical Framework}

The Situation Crisis Communication Theory (SCCT) developed by [32] posits that people involved in a crisis choose what to communicate based on their own goal, reputation, and expected outcomes. Crisis response strategies could range from a simple acknowledgement of what is happening, a denial of a fact, an accusation of some event, or an attack to an interlocutor. Based on empirical evidence, [26] limits the genre of communication practices to five categories: (i) information broadcasting, (ii) warning broadcasting, (iii) appeal for information, (iv) information to encourage helping behaviors, and (v) rumor fighting. Although this typology requires further verification and validation, it seems adequate for the purpose of this study.

In addition to the typology of information exchanged in a crisis situation, Communication Accommodation Theory (CAT) (e.g., [31]) argues that when people communicate with each other they interactively adjust their speech-and to some other extent their patterns and gestures, to accommodate to others. CAT underlines the importance of context and 
identity in people's interactions, and as such, it seems important in the context of this study to take into consideration the various types of convergence behaviors among the general public discussed previously. We assume that since each of the convergence behaviors pursues a different goal (e.g., the "helper" vs. the "exploiter"), their communication style would differ significantly. Internalizing the convergence behavior's view of the crisis situation should provide a truer perspective of how anonymous or unknown interlocutors interact online with the authorities or with other netizens.

A third and last logical step in building our conceptual framework is to put the interplay between the interlocutors (i.e., eight convergence behaviors) and the types of information exchange in the organizational context of a social media platform. Any platform has specific ways of being set up and launched, and particular operating rules. Twitter, as the platform provider, has exact rules regarding posting of texts and emoticons, photos and videos. Scott [33] contends that, for any organization, its legitimacy is defined by its own structure and procedures. To survive, an institution must conform to prevailing rules and belief systems. Operationally, an institution should consist of resilient social structures that are composed of cultural-cognitive, normative, and regulative elements [34]. As such, we looked for the institutional elements that would provide sustainability to the social media for crisis response.

Figure 1 summarizes the theoretical framework of this research anchored in three interacting concepts: crisis communication practices by crisis convergence behaviors, the authorities in charge of emergency responses in the context of institutionalization, and a social media platform. Table 1 describes some of the communication types genres and sub-genres - in a crisis situation.

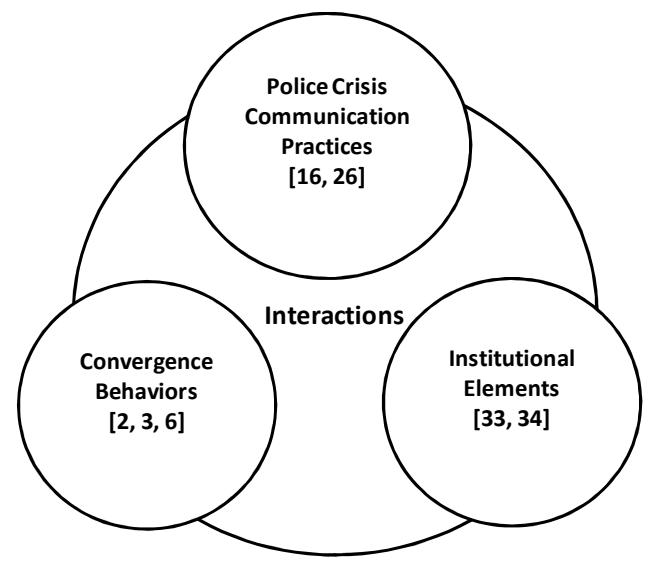

Figure 1: Conceptual Framework

\begin{tabular}{|c|c|c|}
\hline \multicolumn{3}{|r|}{ Table 1: Communication Practices } \\
\hline Genre & Sub-Genre & Descriptions \\
\hline \multirow[t]{6}{*}{$\begin{array}{l}\text { Broadcast } \\
\text { Information }\end{array}$} & Road Information & $\begin{array}{l}\text { Threads with the intention of informing the community about flooded, closed or reopened roads } \\
\text { and intense traffic volume. }\end{array}$ \\
\hline & Flood Information & Threads discussing revoked flood warnings and flood levels of rivers or specific areas. \\
\hline & Weather Information & Information about future rainfall, regular weather events or cancelled weather warnings. \\
\hline & $\begin{array}{l}\text { Information about } \\
\text { Supply }\end{array}$ & Inform the community about imminent re-supply of resources such as food, water, good or gas. \\
\hline & $\begin{array}{l}\text { Information about } \\
\text { Energy Supply }\end{array}$ & $\begin{array}{l}\text { Threads that announce the cutting off, re-supply or availability of electrical power in specific } \\
\text { areas. }\end{array}$ \\
\hline & General Information & Threads with a general information focus and also all threads referring to normal police-work. \\
\hline \multirow[t]{3}{*}{$\begin{array}{l}\text { Broadcast } \\
\text { Warning }\end{array}$} & Flood Warning & Warnings about raise of river flood levels or supposed flood flashing events. \\
\hline & Weather Warning & $\begin{array}{l}\text { Intention to warn the community about intense future weather events like thunderstorms or tropical } \\
\text { cyclones. }\end{array}$ \\
\hline & General Warning & $\begin{array}{l}\text { These warnings are those, which do not fall into the other genres but still warn the community } \\
\text { about threats. }\end{array}$ \\
\hline \multirow[t]{4}{*}{$\begin{array}{l}\text { Encourage } \\
\text { Behavior }\end{array}$} & Navigate Behavior & $\begin{array}{l}\text { Attempt to navigate the community to a specific behavior, like preparing for inundation and not to } \\
\text { enter flood water. }\end{array}$ \\
\hline & $\begin{array}{ll}\text { Appeal for } \\
\text { Volunteers }\end{array}$ & $\begin{array}{l}\text { This genre provides information where volunteers are needed and discussions of individuals } \\
\text { offering themselves. }\end{array}$ \\
\hline & Appeal for Donations & $\begin{array}{l}\text { Threads refer to individuals who are interested in donating and are looking for trustworthy } \\
\text { institutions. It also provides information from different institutions as to where to donate goods or } \\
\text { money. }\end{array}$ \\
\hline & Evacuations & Advice of which areas to evacuate and provides information about evacuation shelters. \\
\hline $\begin{array}{l}\text { Appeal for } \\
\text { Information }\end{array}$ & & $\begin{array}{l}\text { Possibility of two-way communication in Social Media. It is with the intention of getting } \\
\text { information from the community (has no further sub-genre). }\end{array}$ \\
\hline $\begin{array}{l}\text { Fighting } \\
\text { Rumor }\end{array}$ & & $\begin{array}{l}\text { Refers to threads that have the intention to clarify false or misleading information circulating } \\
\text { throughout the community or traditional print media (has no further sub-genre). }\end{array}$ \\
\hline
\end{tabular}




\section{Case Study: The 2015 Nepal Earthquake and Use of Twitter as a Communication Medium}

\subsection{Research Site}

On 25th April 2015, at 11:56 local time, a devastating earthquake of a magnitude of 7.6 on the Richter scale struck Nepal. The epicenter was located in Barpak VDC of the Gorkha District ${ }^{2}$. A subsequent earthquake of magnitude 6.8 struck the nearby Dolakha district on $12^{\text {th }}$ May $2015^{3}$. The disasters caused thousands of deaths and injuries, and displaced millions of people. Immediately after the quakes, several organizations, including the Nepalese government agencies and a score of private citizens, started to utilize social media with the goal of reaching out to the public at large that is involved in the quakes. Among them, the Nepal Police utilized their Facebook page the same day once the Internet connection was restored. It next set up a Twitter account on $27^{\text {th }}$ April to reach out to the general public with specific crisis response recommendations (see Figure 2).

\subsection{Methodology, Data Collection and Analysis}

Studying the interactions between netizens' behaviors and the communication practices of Nepal Police required an understanding of the contextual conditions that could not be replicated in a clinical setting [35, 36]. Rowley \& Slack [37] argue that the strength of case studies lies in the ability to conduct an investigation of a phenomenon in its actual context. We thus adopted an exploratory case study approach.

We used the Netnography [38], an online field study method using participant-observational research, to collect and analyze computer-mediated communications from the Nepal Police Twitter handle (@nepalpolicehq) site for a period ranging from April $27^{\text {th }}$ to $21^{\text {st }}$ May 2015. The Netnography process consists of three main procedures: (i) research planning and entrée; (ii) download of communications of online community members; and (iii) data analysis and interpretation [39]. All the analyzed Tweets were publicly available on @ nepapolicehq handle. Ethical standards were followed as prescribed. We chose not to collect

\footnotetext{
${ }^{2}$ http://drrportal.gov.np/uploads/document/14.pdf

${ }^{3}$ http://drrportal.gov.np/uploads/publication/32.pdf
}

Nepal Police@NepalPoliceHQ.21 May 2015

Please note we are here to support \#NepalEarthquake victims, their families and relief workers. We suggest you to DM non-disaster issues 4 $1720 \quad 024 \quad \ldots$

Nepal Police@NepalPoliceHQ.12 May 2015

Please stay in open field, help us make free road, do not make phone nw busy. SMS is suggested.

h 七า $1.2 \mathrm{~K} \odot 430 \quad \ldots$

Figure 2: Objectives of @nepalpolicehq

profile information of @nepapolicehq handle followers. Members' profile names or handles were coded as "xxxx". With a non-participative and unobtrusive approach [40, 41], our involvement was limited to observing conversations and taking notes. Our note taking was unstructured because the collected data themselves had no specific rules or structure.

We used text mining to classify the convergence behaviors exhibited during and after the two earthquakes. To understand how Nepal Police utilized Twitter to handle crisis communication needs. We next coded the text data according to the genres and sub-genres shown in Table 1. Each Tweet was considered a thread for the analysis. Repeated Tweets were removed from the data. Reviews of postings were carried out and data were studied.

Our coding is based on coding processes suggested by [42] and we followed a mixed approach of coding down "priori" [43] and coding up (emergent and open). During the data analysis process we also followed recommendations suggested by [44] on coding, developing categories, finding relationships, noticing, and uncovering the thinking process behind the sequences of Tweets. Twitter analytics were used to find out about @ nepalpolicehq Tweets, and how they resonate with their audiences. The key metric used was the engagement rate, which is defined as the total number of times a user interacted with a Tweet divided by impressions (times a user is served a Tweet in timeline or search results $)^{4}$.

\section{Analysis and Discussion}

\subsection{An Instantiated Typology of e- Convergence}

The mining of the data collected in this research allowed us to provide an instantiation of the actual type of online convergence behaviors or e-

\footnotetext{
${ }^{4}$ https://support.twitter.com/articles/20171990\#
} 


\begin{tabular}{|l|l|}
\hline \multicolumn{1}{|c|}{$\begin{array}{c}\text { Table 2: Presence of e-convergence behaviors in Nepal } \\
\text { earthquake } \\
\text { convergence }\end{array}$} & \multicolumn{1}{|c|}{ Description } \\
\hline The returnees [R] & $\begin{array}{l}\text { Asked to check their homes, properties and } \\
\text { even cattle they left behind. }\end{array}$ \\
\hline The anxious [A] & $\begin{array}{l}\text { Asked about missing people, makeshift } \\
\text { shelters, water, food and medical support. }\end{array}$ \\
\hline The helpers [H] & $\begin{array}{l}\text { Helped locate informational websites like } \\
\text { mission people. Provide phone numbers. }\end{array}$ \\
\hline The curious [C] & $\begin{array}{l}\text { Asked about their schools, temples and } \\
\text { wanted see pictures. }\end{array}$ \\
\hline The exploiters [E] & $\begin{array}{l}\text { Selling free tarps. Selling historical } \\
\text { artifacts. }\end{array}$ \\
\hline $\begin{array}{l}\text { The fans (supporters) } \\
\text { [F] }\end{array}$ & $\begin{array}{l}\text { Talked good about works of crisis } \\
\text { responders. }\end{array}$ \\
\hline The mourners [M] & $\begin{array}{l}\text { Offered condolences and showed } \\
\text { sympathy. }\end{array}$ \\
\hline The detectives [D] & $\begin{array}{l}\text { Informed about black marketing, extra bus } \\
\text { fares, and suspicious activities. }\end{array}$ \\
\hline Source: [6] & \\
\hline
\end{tabular}

convergences (Table 2). The eight convergence behaviors also found present. However, unlike other studies, this case study found fewer incidents of online exploitations. The reason could be twofold. Nepal's adoption of information and communication technology is still at an early stage. As not many

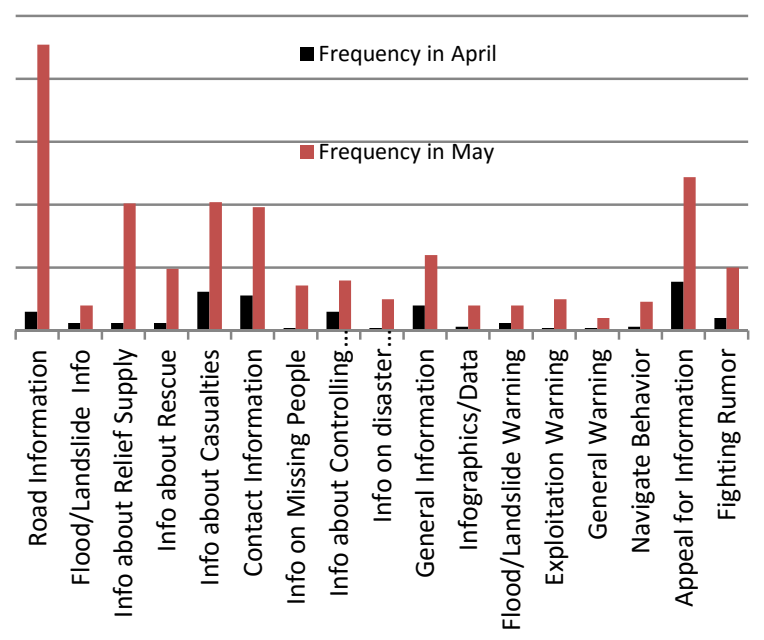

Figure 3: Communication Practices of Nepal Police

people use online financial transactions, exploiters might not have had many opportunities to engage in online scams. Also, exploiters might have stayed away from a site administered by the Police.
Nonetheless, other convergence behaviors like helpers spanned from general public initiatives to large corporations like Google; the latter started a map site dedicated to the earthquake. Helpers posted images, links, maps, and information about different places in Nepal. These data served as a useful visual reference to the anxious and the returnees about what happened in their areas of interest as well as to rescuers and relief workers. Supporters were a unique group of users who supported the helpers by cheering their works. Curious online users looked for reports on damages or landslides. The mourners paid tribute, Tweeting their condolences or posting candle images. The detectives put their surveillance antenna on and reported malicious online threats and fraudulent activities. They warned people not to click malicious links and urged them to donate to official relief agencies only. Overall, data suggested that netizens along with the police were able to collaborate in the fight against online anti-social behaviors. With the presence of an online institutional pillar with the national police as a legitimate governing authority, an official social media site was able to deter the presence of exploiters.

\subsection{Analysis of communication types}

The total number of Tweets in April and May were 231 and 1241, respectively. The number of re-Tweets and replies were 8837 and 597 in the month of April. In the month of May, the number of re-Tweets and replies were 17958 and 1560. The findings of communication practices in April and May based on the Tweets are presented in Figure 3. In May, the road information was on the top of the list and general warning in the bottom. Similarly, appeal for information was highest and general warning the least. This may indicate that during crisis police tend to focus more on the disaster than general police work. Our data indicated that Nepal Police disseminated information on casualties, contact information, disaster community work, and infographics. Table 3 summarizes the key communication themes found in the case study. Most of the communications were similar to a previous study involving the Australian police [26]. The posting of infographics were not part of Queensland Police data. Similarly the encouraging behavior of Nepal Police seem to have only one subtheme, unlike Queensland that had three sub-themes. Our data did not show appeal for volunteers and appeal for donations. 


\subsection{Interaction between convergence behavior and communication types}

With the help of Twitter analytics, users' engagement rate for each Tweet was calculated. For this study purpose, the first 50 Tweets that had the highest engagement rate have been explored during the months of April and May as shown in the Figure 4 and Figure 5 respectively.

The relationship between the Anxious and information on missing persons, and the Curious and appeal for information is the highest, followed by Mourners and information casualties. The relationship between the Curious and fighting rumors is also evident. The Curious were seen asking the police when they saw Tweets about rumors of possible earthquakes or disasters. Similarly, the Detective behaviors of netizens helped the police in controlling exploitations.

The association in Figures 4 and 5 indicates that exploitation behavior was not found in the data. Tweets about Returnees were nonexistent. Surprisingly, victims did not come in contact with police through Twitter, but helpers and curious were seen using the Nepal Police handle.

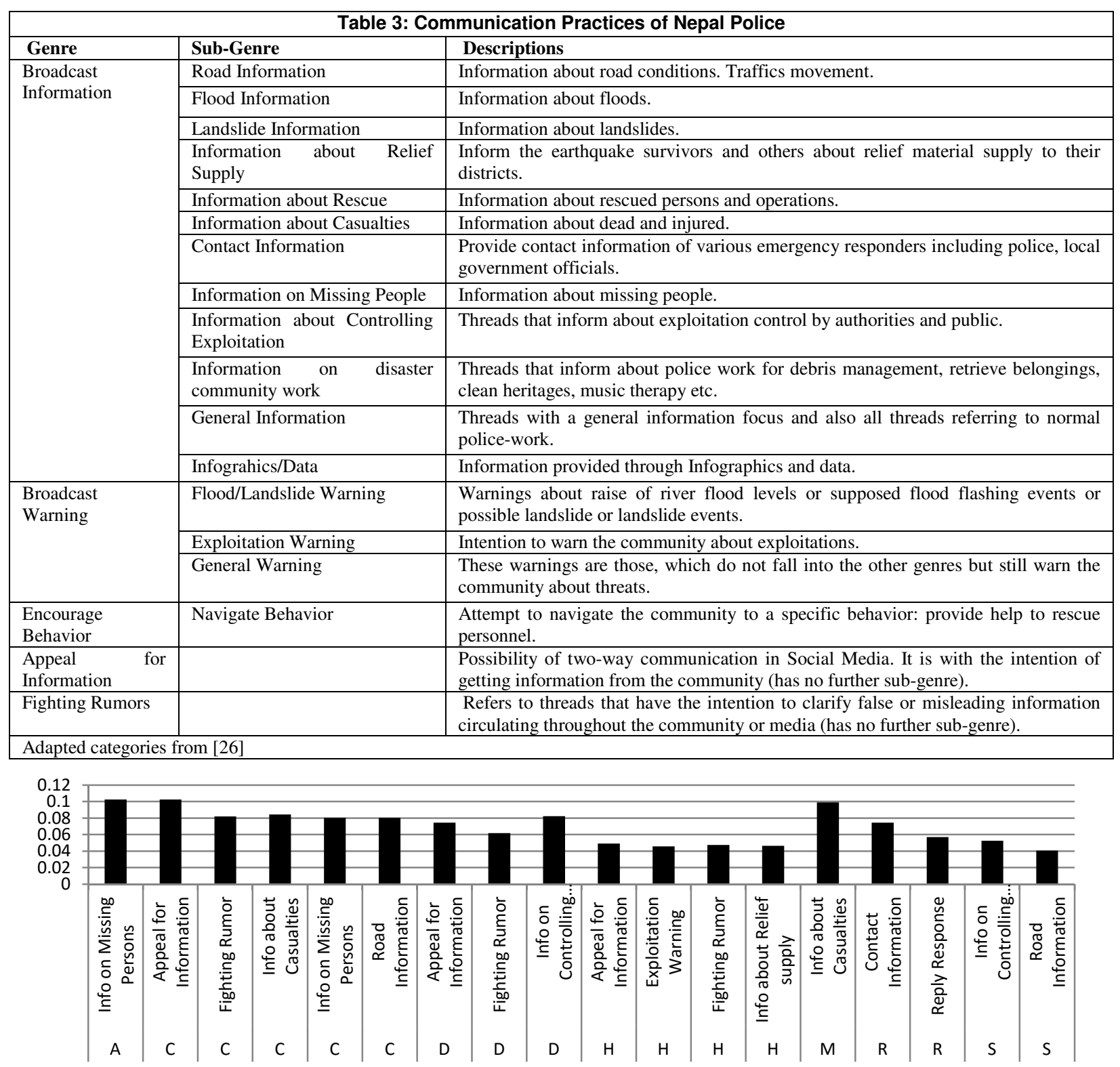

Figure 4: Engagement rate in April 2015 


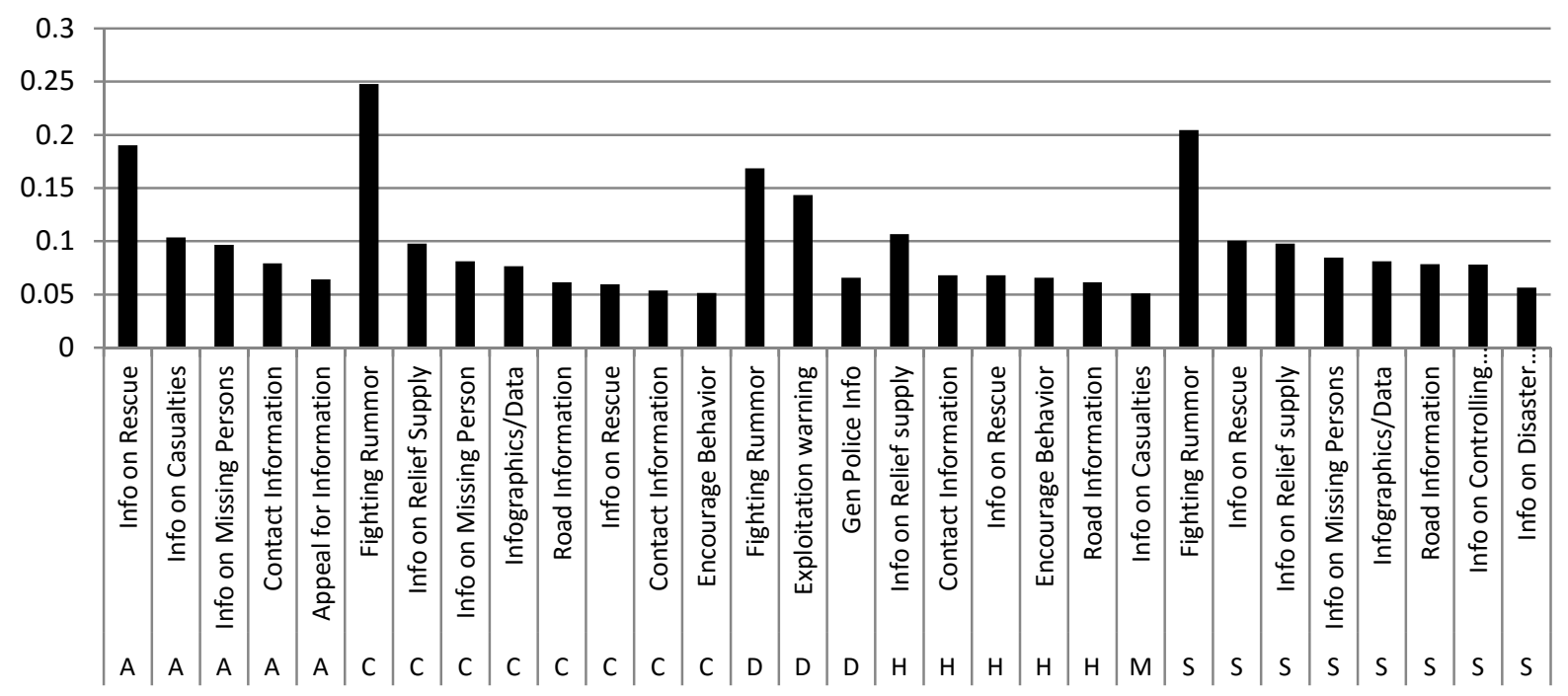

Figure 5: Engagement rate in May 2015

Legend: The convergence behaviors are represented by their first letter (Table 2).

\subsection{Convergence Behaviors, Communication Practices and Institutional Elements}

Institutions consist of regulative, normative, and cultural-cognitive structures and activities that provide meaningful social behavior in social media ecosystems. The Nepal Police Twitter handle was created to provide a platform for crisis response. It had responsibilities of managing the handle and keeping the forum un-disrupted so that followers could give and receive information. These responsibilities rested on the "Twitter handle Manager". However, the operational procedures were guided by Nepal Police as the handle is an official account managed by a group of police officers. We referred them as "eOfficers". As a part of the regulative pillar, Twitter, and the handle eOfficers formulated rules, regulations, norms based on its roles, values, and the purpose of the handle (normative pillar). The normative pillar emphasizes that followers behave appropriately and are compliant with the expected roles based on the values and norms. Monitoring takes place based on these characteristics and the eOfficers ensured that their followers' behaviors were in compliance with its rules, norms and values. Shared beliefs among the group represent the cultural-cognitive pillar that guided the eOfficers and followers to create an ambience for information exchange that benefitted the disaster victims. The interactions created a culture involving followers and institutions such as Nepal
Police, to achieve the concept to help crisis victims through social media.

Regulative systems include rules/norms and purposes of the forum. Twitter mandated that the eOfficers manage the handle, thus providing leadership position. Leadership is one of the powerful institutional characteristics taken up by the eOfficers who could enforce rules when expectations were not met. However, the main authority rested in the hand of Nepal Police leadership, which approved the role of the eOfficers. Such officially sanctioned institutional elements provided ownership to the eOfficers, who could remove out of norm posts, and remove or ban followers. Followers and eOfficers could see whether they were compliant or not in compliance with the rules and norms. When they noticed such behaviors they immediately activated the rule enforcement process by drawing the attention of the eOfficer by mentioning the handle in their Tweets. This is considered a regulative process that consists of rule setting, monitoring, and sanctioning activities. The attempt of the eOfficer to influence behaviors of followers regularly helped develop a pattern of behavior, which, in the long run, gets institutionalized [45]. Followers and eOfficers both played significant roles in meeting the objectives of the forum. Followers often served as front line reporters or detectives who reported any unwanted postings and miscreants. When members saw unwanted postings, they reported them to the handle 
eOfficer who may respond and take necessary action. Therefore, a relationship emerged between them [46] leading to collective actions [47]. The analytic outcomes, as shown in Figures 4 and 5, indicate that the Detective behavior of followers is linked with "Fight Rumor" (one of the communication practices). The followers Tweeted about transport services that were overcharging. They mentioned the Twitter handle of Nepal Police in a belief that appropriate action would be taken. Officials who were managing the handle coordinated with local police to apprehend such service providers based on the information provided by the followers (Figure 6). Their actions were guided by institutional elements like jobs and duty.
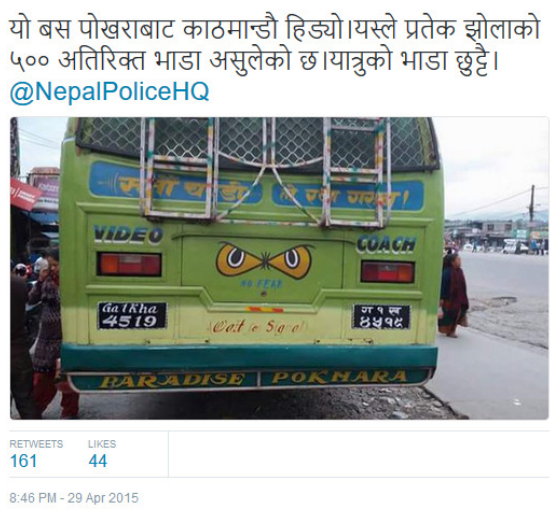

Translation: This bus is going to Pokhara from Kathmandu. It charged extra Rupees 500 for each baggage. In addition to bus fare. @NepalPoliceHQ (The Detective posted a picture of a bus with license plate number 4519.)

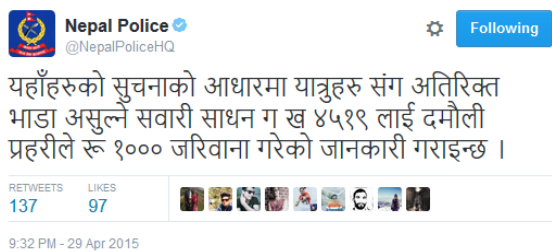

Translation: Based on your information we inform you that the bus \#4519 charging extra fare has been apprehended by a local police office and fined with Rupees 1000.

\section{Figure 6: Detective behavior \& police CCP}

In an online environment, governance seems to be the principal carrier of institutional forces as contended in [33]. Governance is carried out by routines that include protocols and SOPs (Standard Operating Procedure). An example is shown in Figure 7).

Moreover artifacts like a verified profile page or profile picture help in regulation of followers' interactions and behaviors, thus creating a
Nepal Police@NepalPoliceHQ -21 May 2015

We regret that we hv muted\&blocked who doesn't follow norms in spite of our repeated pleas to off limits non-disaster topics on this forum.

4

\section{Figure 7: Implementation of SOPs}

governance structure [49] in virtual communities. Followers felt proud when the Nepal Police handle was verified by Twitter (Figure 8). They felt that they could trust the handle information.

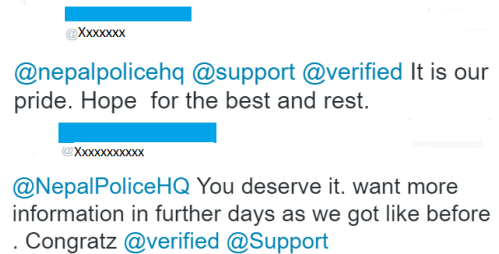

Figure 8: @nepalpolicehq verified

Over time, the number of followers increased and so did their interactions. Thus, logging in from different parts of the world and cultures, netizens got involved in crisis response activities, and eventually developed common understandings and shared beliefs [51]. eOfficers and followers amalgamated to form a shared typification that they needed to be "helping". Moreover, eOfficers were seen trying to maintain good relationships with the followers. They exhibited shared beliefs about helping [50] earthquake survivors. Officials had a relationship with followers who perceived that eOfficers must be online 24/7. One of the habitualized routines of followers was to report to eOfficials, and that prompted eOfficer's day-to-day behavior. From an institutionalization perspective, when the actors (eOfficers and followers) behaved according to the script, the institution was enacted [51].

\section{Summary}

The analysis of the use of Twitter by the national Police headquarters in the aftermath of the 2015 Nepal earthquake demonstrates that Twitter, as a popular social media platform, could be used as an effective communication and collaboration platform between the public authority and the general public, making it easier for the former to serve the community. Information exchange on the status of road situations, casualties, landslides, relief and rescue operations, contacts and missing persons, helped build a collaborative relationship between the handle and followers. Furthermore, the site helped 
highlight the difference in response priorities between the police and the general public, thus allowing the former to reconsider its planning activities.

This case study revealed that not all of the eight convergence behaviors were present. Also, not all convergent behaviors exhibited the same communication needs. The exploitation behavior could only be implied from the information provided by the detectives. As far as institutionalization is concerned, this study was able to find institutional elements that mediated the activities of the Twitter handle of the Nepal Police. However, this finding is still preliminary and further study is needed.

Acknowledgement: We are grateful to Nepal Police for the conduct of the field study, the reviewers for their thorough suggestions, and to Ms. Pamela Estell for her editorial work.

\section{References}

[1] Hauben, M. and R. Hauben, Netizens: On the History and Impact of Usenet and the Internet, Wiley-IEEE Computer Society Press, CA, 1997.

[2] Fritz, C. E., and J. H. Mathewson, "Convergence Behavior in Disasters: A Problem in Social Control". Committee on Disaster Studies, Disaster Research Group, 1957.

[3] Kendra, J. and T. Wachtendorf, "Reconsidering Convergence and Converger Legitimacy in Response to the World Trade Center Disaster," Terrorism and Disaster: New Threats, New Ideas, Research in Social Problems and Public Policy, L. Clarke (Ed.), Elsevier Science Ltd., Vol. 11, 2003, pp. 97-122.

[4] Hughes, A., L. Palen, J. Sutton, S. Liu, and S. Vieweg, "'Site-Seeing' in Disaster: An Examination of On-Line Social Convergence", Proceedings of the 5th International ISCRAM Conference, Washington, DC, USA, F. Fiedrich and B. Van de Walle (Eds.), May, 2008.

[5] Palen, L., R. S. Hiltz, and S. B. Liu, "Online Forums Supporting Grassroots Participation in Emergency Preparedness and Response", Communications of the ACM, 2007, 50 (3), pp.5458.

[6] Subba, R., \& T. Bui, "An Exploration of Physicalonline Convergence Behaviors in Crisis Situations" Proceedings of the 43rd Hawaii International Conference on System Sciences, R. Sprague (Ed.), 2010, pp.1-10,

[7] Wenger, E., N. White, and J. D. Smith, Digital Habitats: Stewarding Technology for Communities, CPsquare, Portland, OR, 2009.

[8] Hiltz, S. R. and M. Turoff, M., The Network Nation, Addison-Wesley, Reading, MA, 1978.
[9] Glaser, M., California Wildfire Coverage by Local Media, Blogs, Twitter, Maps and More, PBS MediaShift, 2007

[10] Sutton, J., L. Palen, L., and I. Shklovski, I., "Backchannels on the Front Lines: Emergent Uses of Social Media in the 2007 Southern California Wildfires ", The Information Systems for Crisis Response and Management (ISCRAM), Washington, DC, 2008.

[11] Vieweg, S., A. Hughes, A., K. Starbird, K., and L. Palen, L., "Microblogging During Two Natural Hazards Events: What Twitter May Contribute to Situational Awareness", Proceedings of the ACM Conference on Computer Human Interaction, 2010, pp. 1079-1088.

[12] Cheong, F. and C. Cheong, "Social Media Data Mining: A Social Network Analysis of Tweets During the 2010-2011 Australian Floods", Pacific Asia Conference on Information Systems, Brisbane, 2011.

[13] Acar, A., and Y. Muraki, "Twitter for Crisis Communication: Lessons Learned from Japan's Tsunami Disaster", International Journal of Web Based Communities, 2011, 7(3), pp 392-402.

[14] Ahmed, A., and J. Sargent, "Analysis of Post-crisis Twitter Communication: A Study of the Iquique, Chile Earthquake", Proceedings of the Australasian Conference on Information Systems, ACIS, 2014.

[15] Radianti, J., S. R. Hiltz, \& L. Labaka, L., “An Overview of Public Concerns During the Recovery Period after a Major Earthquake: Nepal Twitter Analysis", Proceedings of 49th Hawaii International Conference on System Sciences (HICSS), 2016, pp. 136-145

[16] Ehnis, C. and D. Bunker, "The Impact of Disaster Typology on Social Media use by Emergency Services Agencies: The Case of the Boston Marathon Bombing", Proceedings of the 24th Australian Conference on Information Systems, 2013.

[17] Sutton, J. N., E. S. Spiro, B. Johnson, S. M. Fitzhugh, M. Greczek, and C. T. Butts, "Connected communications: network structures of official communications in a technological disaster", Proceedings of the 9th International ISCRAM Conference, L. Rothkrantz, J. Ristvej and Z. Franco (Eds.), 2012,

[18] Condon, S. L., and Jason R. Robinson, "Communication Media Use in Emergency Response Management." Proceedings of the 11th ISCRAM Conference, S.R. Hiltz, M.S. Pfaff, L. Plotnick, and P.C. Shih (Eds.), 2014, pp. 687-696.

[19] Hughes, A. L., L. A. S. Denis, L. Palen, and K. M. Anderson, "Online Public Communications by Police \& Fire Services during the 2012 Hurricane Sandy", Proceedings of CHI, 2014.

[20] Polanyi, M., The Logic of Liberty: Reflections and Rejoinders, Routledge \& Kegan Paul, Oxon, 1951. 
[21] Ostrom, V., Polycentricity (Part 1 and 2), Polycentricity and Local Public Economies: Readings from the Workshop in Political Theory and Policy Analysis, University of Michigan Press, Michigan, Michael D. McGinnis (Ed.),1999, pp.119-138.

[22] Wilson, O. W., and R. C. McLaren, Police administration, McGraw-Hill, New York, 1963

[23] Etling, B., R. Faris, R., and J. Palfrey, "Political Change in the Digital Age: The Fragility and Promise of Online Organizing", SAIS Review of International Affairs, 2010, 30(2), pp.37-49.

[24] Crump, J., "What are the Police Doing on Twitter? Social Media, the Police, and the Public", Policy \& Internet, 2012, 3(4), pp.1-27.

[25] Mastrofski, S. D., Police Organization and Management Issues for the Next Decade, presented at the National Institute of Justice (NIJ) Policing Research Workshop: Planning for the Future, Washington, DC, November 28-29, 2006. Last accessed https://www.ncjrs.gov/pdffiles1/nij/grants/218584.p df on $9 / 1 / 2016$.

[26] Ehnis, C. and D. Bunker, "Social Media in Disaster Response: Queensland Police Service - Public Engagement During the 2011 Floods", 23rd Australian Conference on Information Systems, 2012.

[27] Denef, S., P. S. Bayerl, and N. A. Kaptein, N. A., "Social media and the police: Tweeting practices of british police forces during the August 2011 riots", Proceedings of the SIGCHI conference on human factors in computing systems, ACM, 2013, April, pp. 3471-3480.

[28] Ehnis, C., M. Mirbabaie, D. Bunker, and S. Stieglit, "The Role of Social Media Network Participants in Extreme Events", 25th Australasian Conference on Information Systems, Auckland, New Zealand, 8th 10th Dec, 2014

[29] Heverin, T. and L. Zach, L., Twitter for City Police Department Information Sharing, Proceedings of the Seventy-Third American Society for Information Science and Technology Conference, Pittsburgh, Pennsylvania, 2010.

[30] Brainard, L., and M. Edlins, M., "Top 10 US Municipal Police Departments and Their Social Media Usage", The American Review of Public Administration, 2015, 45(6), pp.728-745.

[31] Giles, H., J. Coupland, and N. Coupland. Contexts of Accommodation: Developments in Applied Sociolinguistics, Cambridge University Press, 1991.

[32] Coombs, W. T., Protecting Organization Reputations During a Crisis: The Development and Application of Situational Crisis Communication Theory, Corporate Reputation Review, 2007, 10, pp.1-14.

[33] Scott, W. R., Institutions and Organizations, Sage, CA, 1995.
[34] Scott, W.R., Institutions and Organizations, Ideas and Interests, Sage, LA, 2008.

[35] Maxwell, J. A., Qualitative Research Design: An Interactive Approach, Sage, CA, 2005.

[36] Yin, R. K., Case Study Research: Design and Methods. Sage: CA, 2003.

[37] Rowley, J. and F. Slack, F., "Conducting a Literature Review", Management Research News, 2006, 27(6), pp.31-39.

[38] Kozinets, R. V., Netnography, Doing Ethnographic Research Online, Sage, CA, 2010.

[39] Kozinets, R. V., "The Field Behind the Screen: Using Netnography for Marketing Research in Online Communities," Journal of Marketing Research, Feb, 2002, 39, pp.61-72.

[40] Mann, D and M. Sutton, "Netcrime: More Change in the Organization of Thieving", The British Journal of Criminology, 1998, 38(2), pp.201-229.

[41] Pollock, E. T., "Understanding and Contextualizing Racial Hatred on the Internet: A Study of Newsgroups and Websites", The Internet Journal of Criminology, 2006.

[42] Strauss, A. and J. Corbin, Basics of Qualitative Research: Techniques and Procedures for Developing Grounded Theory, Sage, CA, 1998.

[43] Saldaña, J., The Coding Manual for Qualitative Researchers, Sage, CA, 2015.

[44] Seidel, J., Qualitative Data Analyisis, The Ethnograph v5 Manual, Appendix E, 1998, last accessed at http://www.qualisresearch.com/DownLoads/qda.pdf on 09/01/2016.

[45] Przeworski, A., "Institutionalization of Voting patterns, or is Mobilization the Source of Decay?", The American Political Science Review, 1975, 69 (1), pp. 49-67.

[46] Scott, W.R., Institutions and Organizations, Ideas, Interests and Identities, Sage, CA, 2001

[47] Ostrom, E., "Collective Action and the Evolution of Social Norms", The Journal of Economic Perspectives, 2000, 14(3), pp. 137-158.

[48] Hercheui, M.D., "A Literature Review of Online Communities: The Relevance of Understanding the Influence of Institutions on Online Collectives", Information, Communication and Society, 2011, 14(1), pp.1-23.

[49] Scott, W. R., "Institutional carriers: Reviewing modes of Transporting Ideas Over Time and Space and Sonsidering Their Consequences", Industrial and Corporate Change, 2003, 12, pp. 879-94.

[50] Kunda, G., Engineering Culture: Control and Commitment in a High-tech Corporation, Temple University Press, Philadelphia, 1992.

[51] Bjorck, F., Institutional theory: A new perspective for research into IS/IT security in organization, Proceedings of the 37th Hawaii International Conference on System Sciences, 2004.

[52] Hagler, G., Careers as a First Responder, Rosen Publishing, NY, 2013. 